\title{
Impacts of natural disasters on a dynamic economy
}

\author{
Andreas Groth, ${ }^{1,2}$ Patrice Dumas, ${ }^{3,1}$ Michael Ghil, ${ }^{1,2,4}$ and Stéphane Hallegatte ${ }^{3,5}$
}

\begin{abstract}
This paper presents a modeling framework for macroeconomic growth dynamics; it is motivated by recent attempts to formulate and study "integrated models" of the coupling between natural and socio-economic phenomena. The challenge is to describe the interfaces between human activities and the functioning of the earth system. We examine the way that this interface works in the presence of endogenous business cycle dynamics, based on a non-equilibrium dynamic model. Recent findings about the macroeconomic response to natural disasters in such a nonequilibrium setting have shown a more severe response to natural disasters during expansions than during recessions. These findings raise questions about the assessment of climate change damages or natural disaster losses that are based purely on long-term growth models. In order to compare the theoretical findings with observational data, we analyze cyclic behavior in the U.S. economy, based on multivariate singular spectrum analysis. We analyze a total of nine aggregate indicators in a 52-year interval (1954-2005) and demonstrate that the behavior of the U.S. economy changes significantly between intervals of growth and recession, with higher volatility during expansions.

KEYWORDS - Business cycle; Macroeconomic dynamics; Multivariate singular spectrum analysis; Nonequilibrium modeling; Nonlinear fluctuation dissipation; Vulnerability paradox
\end{abstract}

\section{Introduction}

The Fourth Assessment Report (AR4) of the Intergovernmental Panel on Climate Change (IPCC) [IPCC, 2007] provides further evidence for global warming and for the significant contribution of anthropogenic greenhouse gases (GHGs) to this warming. Substantial uncertainties remain, however, regarding the degree of warming, and the part of natural variability in it. Even more controversial are the socio-economic consequences of climate change, as well as the costs of reducing GHG emissions and of adapting to a changing climate.

There are numerous difficulties in trying to study the coupled behavior of the socio-economic system and the climate system, each of which is highly complex and nonlinear, and possess variability on a wide range of time and space scales. The assessment of interactions between the two systems posed a difficult organizational problem to the IPCC: socio-economical scientists develop so-called "emission scenarios" that are passed on to the natural scientists, in order to simulate climate change according to them and to derive the future range of temperature increases. The results of these future-climate simulations are then used in impact and adaptation studies to evaluate the associated damages.

Since no real feedbacks are taken into consideration in this exchange-of-information process, the IPCC requested

\footnotetext{
${ }^{1}$ Environmental Research \& Teaching Institute, Ecole Normale Supérieure, Paris, France

${ }^{2}$ Laboratoire de Météorologie Dynamique (CNRS and IPSL), Ecole Normale Supérieure, Paris, France

${ }^{3}$ Centre International de Recherche sur l'Environnement et le Développement, Nogent-sur-Marne, France

${ }^{4}$ Department of Atmospheric \& Oceanic Sciences and Institute of Geophysics \& Planetary Physics, University of California, Los Angeles, USA

${ }^{5}$ Ecole Nationale de la Météorologie, Météo France, Toulouse, France
}

Copyright 2011 by the American Geophysical Union. 0148-0227/11/\$9.00 the preparation of a new set of scenarios to facilitate future assessments of climate change. The introduction of Representative Concentration Pathways (RCPs) [Moss et al., 2010] into the next Assessment Report (AR5) aims to improve the exchange of information among natural and social scientists. Although these RCPs expedite climate modeling in parallel with the development of socio-economic and emission scenarios, the problems due to a lack of real feedbacks between the two systems - and to real communication between the research communities that study each of them separately [Wittgenstein, 2001; Hillerbrand and Ghil, 2008] - persist. There are several truly coupled "integrated assessment models" [e.g., Ambrosi et al., 2003; Nordhaus and Boyer, 1998; Stern, 2006], but they disregard variability and represent both climate and the economy as a succession of equilibrium states without endogenous dynamics.

The detailed dynamic modeling of the two systems is, however, still out of reach, as our understanding of the complex dynamics of either system, as well as of their coupling, is rather incomplete. For this reason, we advocate an approach based on a hierarchy of models, from simple, conceptual "toy models" all the way to complex detailed models. This approach has become fairly widespread in climate dynamics [Ghil, 2001; Ghil et al., 2008a] and it allows us to give proper weight to the understanding of the underlying mechanisms given by the simpler models, on the one hand, and to the realism of the more detailed models, on the other. In modeling physico-chemical, ecological, or socio-economic processes, this means starting with toy models and climbing up the modeling ladder, rung by rung, towards more complex models, while always comparing the results with increasingly detailed observational data.

The work presented here describes, on the level of simple and highly idealized models, the impact of extreme climatic events on a non-equilibrium dynamic model (NEDyM) of the economy. After a brief description of the economic model and of its business cycles in the next section, we consider in Section 3 the impact of natural disasters on this model's dynamical behavior, and present some recent results concerning a "vulnerability paradox" that arises from the presence of cyclic behavior, namely the greater impact of external 
shocks on a given, out-of-equilibrium economy during expansions rather than during recessions.

This paradox suggests that a non-equilibrium version of fluctuation-dissipation theory (FDT) might be at work in such an idealized economy that possesses endogenous business cycles (EnBCs). Motivated by this conjecture and by the desire to validate the presence of EnBCs in real economies, we address in Section 4 the problem of extracting relevant information about business cycles from observational data. Singular spectrum analysis (SSA) is used on 52 years of U.S. economic indicators and the results appear to support the theoretical findings of phase-dependent vulnerability patterns. Finally, we conclude in Section 5 with a summary of results and an outlook on ongoing and future research.

\section{Business cycle dynamics}

Ups and downs in prices and in economic activity have been discussed at least as far back as the seminal work of Smith [1776] and Ricardo [1810]. Beside a long-term upward drift, macroeconomic time series exhibit short-term fluctuations (Fig. 1). There is a long history of attempts to study the characteristics and stylized facts of these fluctuations [Burns and Mitchell, 1946; Kydland and Prescott, 1998]. To this day, the cyclical characteristics of economic behavior, referred to as business cycles, are explained by two main approaches that we briefly review in the following.

\subsection{Real business cycles (RBCs)}

The dominant approach today is known as real business cycle $(R B C)$ theory and is implemented within stochasticdynamic models called general equilibrium models; in this context, "real" refers to the nature of the goods involved,

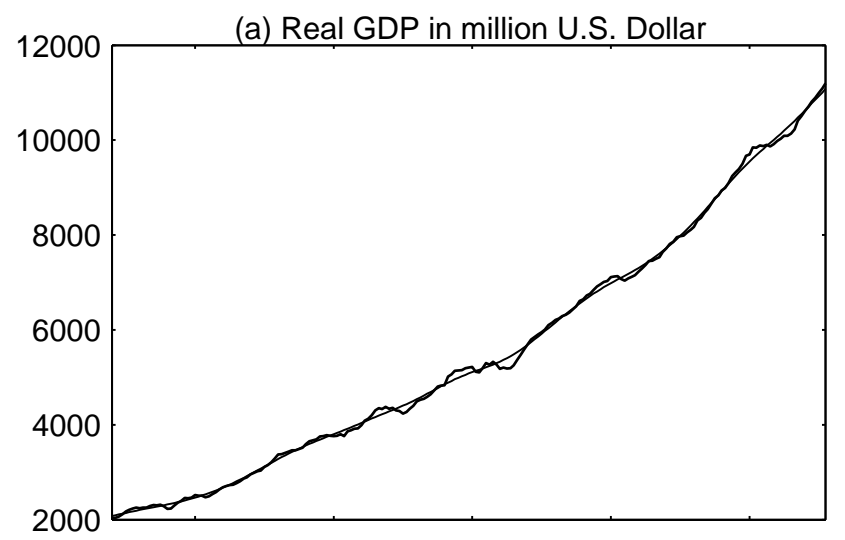

(b) Trend deviations

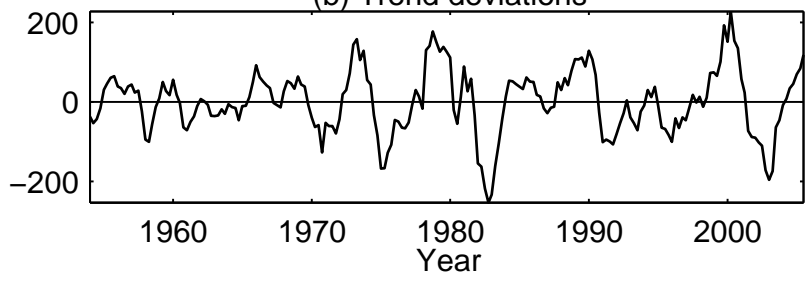

Figure 1. (a) Development of the real gross domestic product (GDP) in the U.S. (heavy curve) and a fitted trend (light curve). (b) Deviations of the GDP from the trend. The trend has been fitted using the Hodrick and Prescott [1997] filter with the parameter value $\lambda=1600$. to distinguish them from monetary and financial aspects of the economy. RBC theory originated in the work of Slutsky [1927] and Frisch [1933], while Kydland and Prescott [1982] embedded this theory into the framework of general equilibrium modeling with rational expectations.

In $\mathrm{RBC}$ theory, it is assumed that economic fluctuations arise exclusively from exogenous shocks and that the economic system is otherwise stable, i.e. that the fluctuations induced by the shocks will be damped to equilibrium. It follows that the system is entirely self-regulating and that there is no point in intervening in it.

\subsection{Endogenous business cycles (EnBCs)}

The second approach is known as endogenous business cycle $(E n B C)$ theory: it proposes that economic fluctuations are due to intrinsic processes that endogenously destabilize the economic system [e.g., Kalecki, 1937; Harrod, 1939; Kaldor, 1940; Samuelson, 1939; Hicks, 1950; Goodwin, 1967; Day, 1982; Grandmont, 1985; Chiarella et al., 2005]. These intrinsic processes may involve various instabilities and nonlinear feedbacks within the economic system itself. It follows that socio-political intervention might help control the mean, period or other features of the cycles.

Both theories have their successes and shortcomings, but it is RBC theory that garners consensus in the current economic literature.

The interplay between natural and economic variability depends to a considerable extent on the underlying economic mechanisms; therefore, overcoming the controversy between the EnBC and RBC theories could facilitate the study of interactions between the climatic and the economic system.

Exogenous shocks in real goods clearly play an important role in business cycles; e.g., the strong economic expansion of the late 1990s was obviously driven by the rapid development of new technologies. Increasing interest in RBC models since the work of Kydland and Prescott [1982] has led to good matches between multi-variable, detailed versions of such models and actual historical data, which have been compiled and become widely available during this time interval [e.g., King and Rebelo, 2000].

Endogenous fluctuations, however, have their part in generating and shaping the cycles, too. Even within the neoclassical tradition, with perfect markets and rational expectations, Day [1982], Grandmont [1985], Gale [1973], and Benhabib and Nishimura [1979] proposed models in which endogenous fluctuations arise from savings behavior, wealth effects and interest-rate movement, or from interactions between overlapping generations and between different sectors. Leading practitioners, like G. Soros, even blame the equilibrium paradigm for its role in helping bring about the current economic and financial crisis: "The currently prevailing paradigm, namely that financial markets tend towards equilibrium, is both false and misleading; our current troubles can be largely attributed to the fact that the international financial system has been developed on the basis of that paradigm" [Soros, 2008].

Market frictions, imperfect rationality in expectations or aggregation biases can give rise to strongly destabilizing processes within the economic system. Numerous authors have proposed accounting for such processes and noted their importance. Harrod [1939] stated that the economy was unstable because of the absence of an adjustment mechanism between population growth and labor demand, although Solow [1956] suggested later that such a mechanism was provided by the producer's choice of the labor-vs.-capital intensity.

Kalecki [1937] and Samuelson [1939] proposed simple business cycle models based on a Keynesian acceleratormultiplier effect and on delayed investing. Later on, Kaldor [1940], Hicks [1950] and Goodwin [1951, 1967] developed 
business cycle models in which the destabilizing process was still the Keynesian accelerator-multiplier, while the stabilizing processes were financial constraints, distribution of income or the role of the reserve army of labor. In Hahn and Solow [1995, Chapter 6], fluctuations can arise from an imperfect goods market, from frictions in the labor market, and from the interplay of irreversible investment and monopolistic competition.

EnBC theory was studied quite actively in the middle of the 20th century but much less so over the last quarter century or so. This fall from favor was due a shift toward rational expectations, i.e. the assumption that all economic agents use all the available information, know perfectly the economic system, and anticipate as well as possible future economic variables [Sargent, 1971, 1973; Lucas, 1972, 1973]. In other terms, agents' predictions of the future value of all variables are not systematically biased, and all errors are random.

Still, Hillinger [1992], Jarsulic [1993], Flaschel et al. [1997], Nikaido [1996], Chiarella and Flaschel [2000], Chiarella et al. [2005] and Hallegatte et al. [2008], among many others, have recently proposed EnBC models and further investigated their properties. The business cycles in these models arise from nonlinear relationships between economic aggregates and are consistent with certain realistic features of actual business cycles.

Due to the relatively limited recent interest in EnBC models, less progress has been made so far in matching their results to the historical data. Even so, Chiarella et al. [2006] showed that their model is able to reproduce historical series when utilization data are taken as input. It is not surprising, moreover, that EnBC models with only a few state variables - typically less than a few dozen - were unable to reproduce the details of historical information that involves processes lying explicitly outside the scope of an economic model (e.g., geopolitical events).

\subsection{EnBCs in a non-equilibrium model}

The non-equilibrium dynamical model (NEDyM) of $\mathrm{Hal}$ legatte et al. [2008] is a neoclassical model with myopic expectations. Key features of the model are the adjustment delays that have been introduced into the clearing mechanisms of the labor and goods markets, as well as into the investment response to profitability signals. It is a highly idealized model that represents an economy with one producer, one consumer, and one type of goods that is used both to consume and invest.

NEDyM is based on the Solow [1956] model, in which all equilibrium constraints are replaced by dynamic relationships that involve adjustment delays. The model has eight state variables - which include production, capital, number of workers employed, wages and prices - and the evolution of these variables is modeled by a set of ordinary differential equations. In Appendix A, we give a brief summary of the model equations; for a more detailed explanation, see $\mathrm{Hal}$ legatte et al. [2008].

NEDyM's main control parameter is the investment flexibility $\alpha_{\text {inv }}$, which measures the adjustment speed of investments in response to profitability signals. This parameter describes how rapidly investment can react to a profitability signal: if $\alpha_{\text {inv }}$ is very small, investment decreases very slowly when profits are small; if $\alpha_{\mathrm{inv}}$ is very large, investment soars when profits are high and collapses when profits are small. Introducing this parameter is equivalent to allocating an investment adjustment cost, as proposed by Kydland and Prescott [1982] and Kimball [1995], among others; these authors found that introducing adjustment costs and delays helps enormously in matching key features of macroeconomic models to the data.

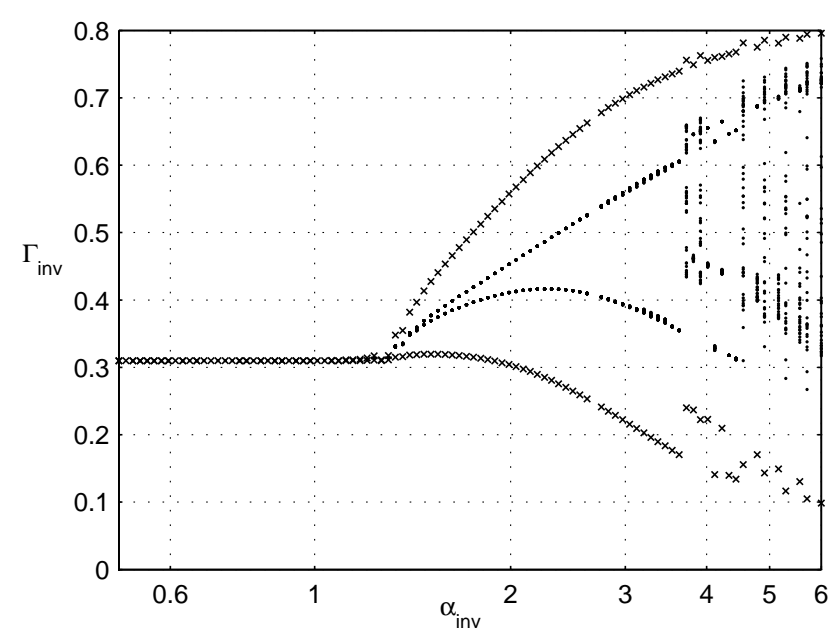

Figure 2. Bifurcation diagram of NEDyM, with the investment parameter $\alpha_{\text {inv }}$ on the abscissa and the investment ratio $\Gamma_{\text {inv }}$ on the ordinate. The model has a unique, stable equilibrium for low values of $\alpha_{\text {inv }}$, and the diagram shows the corresponding value of $\Gamma_{\text {inv }}$ : small ' $\mathrm{x}$ ' symbols indicate, first the stable equilibrium and then the minima and maxima of the trajectory, and small dots the Poincaré intersections at $H=0$, when the goods inventory $H$ vanishes. With increasing $\alpha_{\text {inv }}$, a Hopf bifurcation at $\alpha_{\text {inv }} \simeq 1.39$ leads to a limit cycle, while a transition to chaos occurs at $\alpha_{\text {inv }} \simeq 3.8$.

In NEDyM, investment flexibility has a major influence on economic dynamics. For small $\alpha_{\text {inv }}$, i.e. slow adjustment, the model has a stable equilibrium, which has been calibrated to the economic state of the European Union (EU15 ) in 2001 [Eurostat, 2002]. As the adjustment flexibility increases, this equilibrium loses its stability and undergoes a Hopf bifurcation, after which the model exhibits a stable periodic solution [Hallegatte et al., 2008].

Business cycles in NEDyM originate from the instability of the profit-investment relationship, which is quite similar to the Keynesian accelerator-multiplier effect. Furthermore, the cycles are constrained and limited in amplitude by the interplay of three processes: (i) A reserve army of labor effect, namely the increase of labor costs when the employment rate is high; (ii) the inertia of production capacity; and (iii) the consequent inflation in goods prices when demand increases too rapidly.

The model's bifurcation diagram is shown in Fig. 2, where the values of the other parameters are given in Table 3 of Hallegatte et al. [2008]. For somewhat greater investment flexibility, the model exhibits chaotic behavior, because a new constraint intervenes, namely limited investment capacity. In this chaotic regime, the cycles become quite irregular, with sharper recessions and recoveries of variable duration.

In the present paper, we concentrate, for the sake of simplicity, on model behavior in the purely periodic regime, i.e. we have regular EnBCs, but no chaos. Such periodic behavior is illustrated in Fig. 3.

The NEDyM business cycle is consistent with many stylized facts described in the macroeconomic literature, such as the phasing, or co-movements of the distinct economic variables along the cycle. The model also reproduces the observed asymmetry of the cycle, with the recession phase much shorter than the expansion phase. This typical sawtooth shape of business cycle is not well captured by RBC models, whose linear, auto-regressive character gives intrinsically symmetric behavior around the equilibrium. The amplitude of the price-wage oscillation, however, is too large in 
NEDyM, calling for a better calibration of the parameters and further refinements of the model.

In the setting of the recent economic and financial crisis, the banks' and other financial institutions' large losses have clearly reduced access to credit; this reduction obviously affects very strongly investment flexibility. The EnBC model considered herein can thus help explain how such a change in $\alpha_{\text {inv }}$ can seriously perturb the behavior of the entire economic system, by either increasing or decreasing the variability in macroeconomic variables. Moreover, these losses also lead to a reduction in aggregated demand; this, in turn, can lead to a reduction in economic production and a full-scale recession. While the latter processes are captured by NEDyM, detailed predictions are way beyond the province of such a toy model, and would require, in particular, the "tuning" of its parameters to actual economic data, as currently done for RBC models.

\section{Natural disasters in a dynamic economy}

The dynamics of reconstruction are a major concern when considering the socio-economic consequences of natural disasters. Aside from the immediate damage caused by such a disaster, it is the length and other characteristics of the reconstruction period that will determine the disaster's full cost. Reconstruction may lead to an increase in productivity, by allowing for technical changes to be embedded into
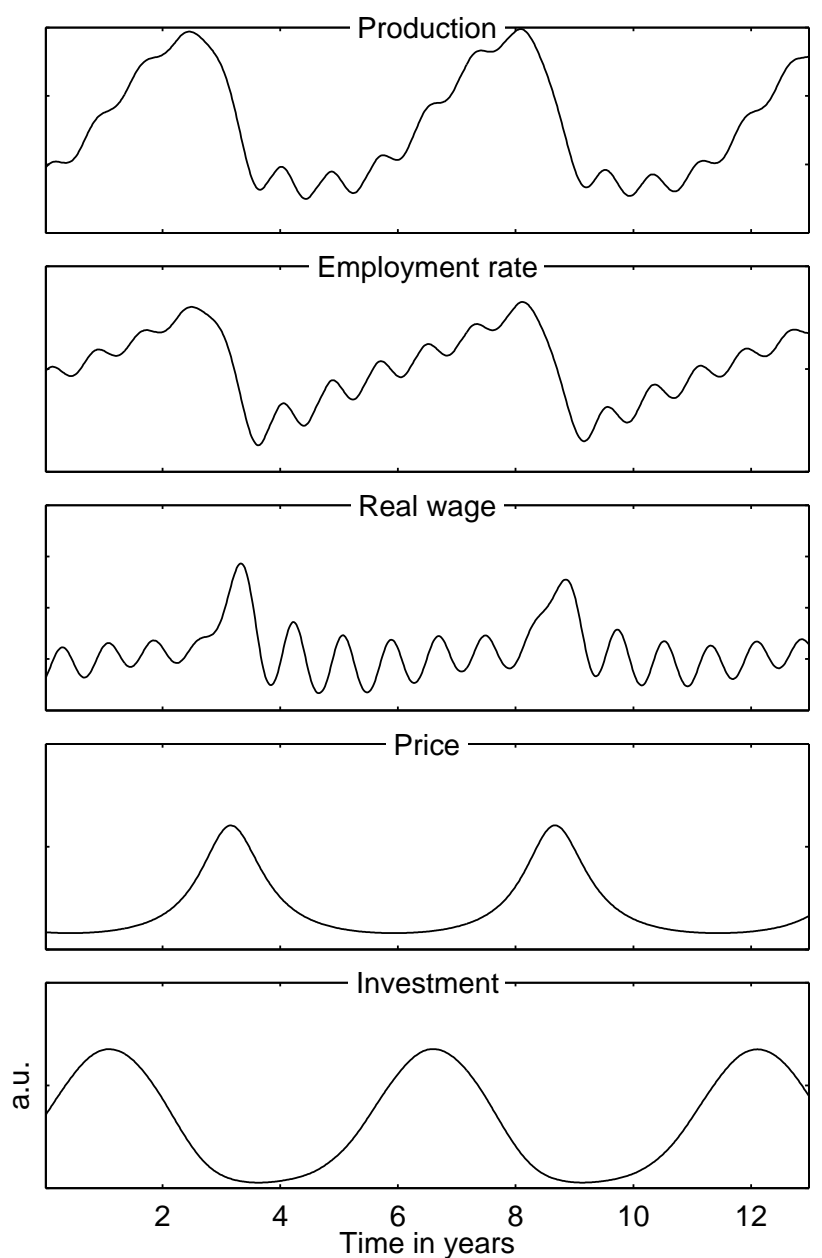

Figure 3. Limit cycle behavior of NEDyM for an investment flexibility of $\alpha_{\text {inv }}=2.5$; all other parameter values as in Table 3 of Hallegatte et al. [2008]. the reconstructed capital; technical changes could also sustain the demand and help economic recovery. At the same time, economic productivity may be reduced during reconstruction because some vital sectors are not functional, and reconstruction investments crowd out investment into new production capacity.

In this section, we briefly review recent findings on reconstruction costs using NEDyM [Hallegatte and Ghil, 2008] and show that it is especially the transition from equilibrium to non-equilibrium behavior that changes and complicates the response to exogenous shocks and the dynamics of reconstruction. This is a critical question in the assessment of natural disasters, since Benson and Clay [2004], among others, have suggested that the overall cost of a natural disaster might depend on the preexisting economic situation. As an example, the Marmara earthquake in 1999 caused destructions that amounted to $1.5-3 \%$ of Turkey's GDP; its cost in terms of production loss, however, is believed to have been kept at a relatively low level by the fact that the country was experiencing a strong recession of $-7 \%$ of GDP in the year before the disaster [Bank, 1999].

Even as simple a model as NEDyM shows that the longterm effects of a sequence of extreme events depend upon the behavior of the economy: an economy that is in stable equilibrium and has only very little flexibility or none $\left(\alpha_{\mathrm{inv}}=0\right.$, cf. Fig. 2) is more vulnerable than a more flexible economy, albeit still at or near equilibrium (e.g., $\alpha_{\text {inv }}=1.0$ ). Clearly, if investment flexibility is null or very low, the economy is incapable of responding to the natural disasters through investment increases aimed at reconstruction; total production losses, therefore, are quite large. Such an economy behaves according to a pure Solow [1956] growth model, where the savings, and therefore the investment, ratio is constant; see the comparative Table 1 in Hallegatte and Ghil [2008].
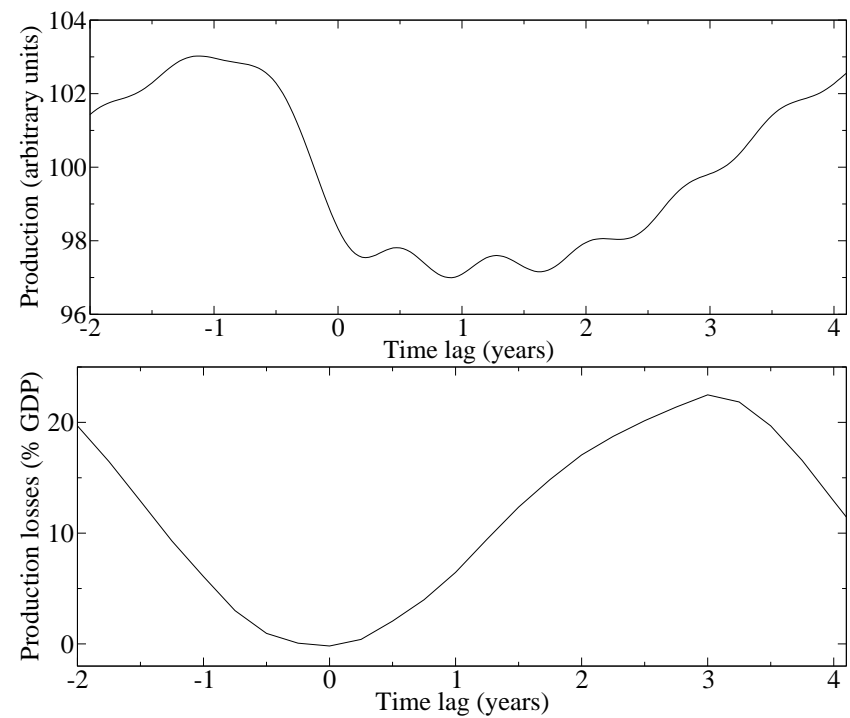

Figure 4. The effect of a single natural disaster on an endogenous business cycle (EnBC). Upper panel: the business cycle in terms of annual production, as a function of time, starting at the cycle minimum (time lag $=$ 0 ). Lower panel: total production losses due to a disaster that instantaneously destroys $3 \%$ of gross domestic product (GDP), shown as a function of the cycle phase in which the disaster occurs; phase measured as time lag with respect to cycle minimum. A disaster occurring near the cycle's minimum causes a limited indirect production loss, while a disaster occurring during the expansion leads to a much larger loss. From Hallegatte and Ghil [2008]. 
When investment can respond to profitability signals without destabilizing the economy, i.e. when $\alpha_{\text {inv }}$ is nonzero but still lower than the critical bifurcation value of $\alpha_{\mathrm{inv}} \simeq$ 1.39, the economy has greater freedom to improve its overall state and thus respond to productive capital influx. Such an economy is much more resilient to disasters, because it can adjust its level of investment in the disaster's aftermath.

If investment flexibility $\alpha_{\text {inv }}$ is larger than its Hopf bifurcation value, the economy undergoes periodic EnBCs and, along such a cycle, NEDyM passes through phases that differ in their stability. This in turn leads to a phase-dependent response to exogenous shocks and consequently to a phasedependent vulnerability of the economic system.

Hallegatte and Ghil [2008] investigated how the state of the economy may influence the consequences of natural disasters. In doing so, these authors introduced into NEDyM the disaster-modeling scheme of Hallegatte et al. [2007], in which natural disasters destroy the productive capital through a modified production function (see Appendix A). Furthermore, to account for market frictions and constraints in the reconstruction process, the reconstruction expenditures are limited.

In this setting, Hallegatte and Ghil [2008] found a remarkable vulnerability paradox: the indirect costs caused by extreme events during a growth phase of the economy are much higher than those that occur during a deep recession. Figure 4 illustrates this paradox, by showing in its upper panel a typical business cycle and in the lower panel the corresponding losses for disasters hitting the economy in different phases of this cycle.

Such an apparent paradox, however, can be easily explained: disasters during high-growth periods enhance preexisting disequilibria. Inventories are low and cannot compensate the reduced production; employment is high, and hiring more employees induces wage inflation; and the producer lacks financial resources to increase his/her investment. The opposite holds during recessions, as mobilizing investment and labor is much easier.

As a consequence, production losses due to disasters that occur during expansion phases are strongly amplified, while they are reduced when the shocks occur during the recession phase. On average, however, (i) expansions last much longer than recessions, in our NEDyM model as well as in reality; and (ii) amplification effects are larger than damping effects. It follows that the net effect of the cycle is strongly unfavorable to the economy, with an average production loss that is almost as large, for $\alpha_{\mathrm{inv}}=2.5$, as for $\alpha_{\mathrm{inv}}=0$; see Table 1 in Hallegatte and Ghil [2008].

The results reviewed here suggest the existence of an optimal investment flexibility; this flexibility allows the economy to react in an efficient manner to exogenous shocks, without provoking endogenous fluctuations that would make it too vulnerable to such shocks. Therefore, according to the NEDyM model, stabilization policies may not only help prevent recessions from being too strong and costly; they may also help control expansion phases, and thus prevent the economy from becoming too vulnerable to unexpected shocks, like natural disasters or other supply-side shocks. Examples of the latter are energy-price shocks, like the oil shock of the 1970s, and production bottlenecks, for instance when electricity production cannot satisfy the demand from a growing industrial sector [Hallegatte and Ghil, 2008].

Applied to the specific issue of climate change, the results in this section highlight the importance of taking into account the presence of endogenous variability in assessing reconstruction costs in general, and the evolution of the economy through several EnBCs in particular. The inclusion of endogenous dynamics suggests that GDP losses may be larger than those obtained by the use of optimization strategies based on equilibrium models [e.g., Ambrosi et al., 2003; Nordhaus and Boyer, 1998; Stern, 2006]. Moreover, the allocation of capital between reconstruction and other types of investment after a large natural disaster can play an important role in both short- and long-term production losses. Optimizing this allocation, therefore, according to the state of the economy when disasters may strike is an important factor in dealing with the expected change in the distribution of extreme events, due to global warming.

\section{Validation with U.S. economic indicators}

Besides a long-term trend in production and material well-being, macroeconomic time series exhibit short-term fluctuations with certain cyclical characteristic (see again Fig. 1). In this section, we focus on the extraction of fundamental dynamical behavior from such time series and evaluate the the consistency of the behavior so obtained with endogenous dynamics. This is an essential step in assessing the reliability of NEDyM results and especially of its behavior with respect to exogenous shocks.

In this context, it is of particular interest whether the predicted vulnerability pattern of NEDyM is also present in the data at hand. Indeed, the fluctuation dissipation theorem (FDT) of statistical physics [Einstein, 1905; Kubo, 1966] states that a system with many degrees of freedom near equilibrium reacts in the same way to an internal as well as to an external shock: the fluctuations to which the shock gives rise die out in the same way.

This property is very useful in estimating the response of such a system to an external shock, since one can compute its properties, in particular the dissipation rate of the fluctuations, from its long-term behavior while it is only subject to internal shocks. Furthermore, fluctuation dissipation theory for systems out of equilibrium (also abbreviated as FDT) indicates that similar properties hold under suitable
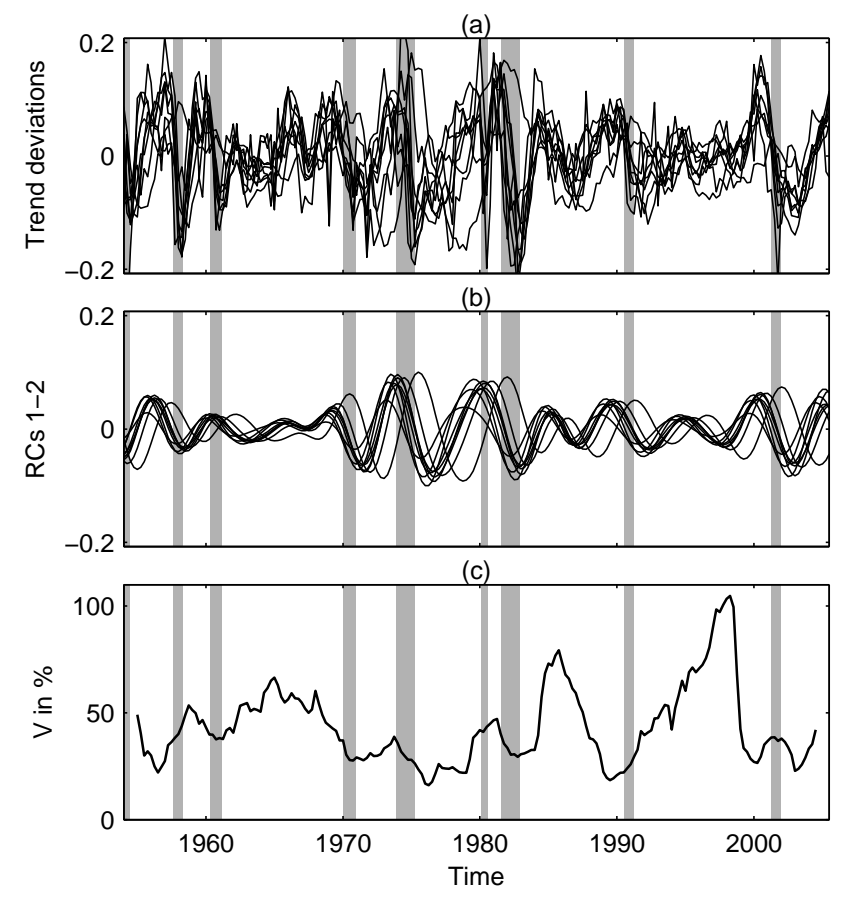

Figure 5. Time series of nine U.S. macroeconomic indicators, 1954-2005. (a) Normalized trend residuals; (b) data-adaptively filtered business cycle, captured by the leading oscillatory pair of M-SSA; and (c) local variance of fluctuations. The shaded vertical bars indicate the NBER-defined recessions. 
assumptions, at least while the response is linear [Ruelle, 2009; Chekroun et al., 2011].

\subsection{Macroeconomic data set}

The data set we use here is quarterly U.S. macroeconomic data from the Bureau of Economic Analysis for 1954 to 2005; see http://www.bea.gov/. The nine time series we use are GDP, investment, consumption, employment rate (in \%), total wage, change in private inventories, price, exports, and imports. As commonly done in econometrics, we first remove the trend and convert the data to relative values by dividing the data points by the corresponding trend values. A typical filter used in the economic literature for extracting the trend is the Hodrick-Prescott filter [Hodrick and Prescott, 1997]. Next, all time series are normalized by their standard deviation. The series, after being thus detrended and normalized, are shown in Fig. 5(a).

All nine time series in the figure exhibit fluctuations of varying amplitude and period. These fluctuations could be induced by external shocks, such as political events and natural disasters, or by intrinsic macroeconomic processes. Whatever the causes, a predominantly cyclical behavior is clearly visible. In order to assess from such a short and noisy time series whether this cyclicity is significant or is merely due to chance, we decompose the full set of nine indicators into its spectral components with the help of multivariate singular spectrum analysis (M-SSA) and apply statistical Monte Carlo tests. Appendix B contains a brief description and explanation of the M-SSA methodology.

\subsection{Cyclical behavior}

The first result of the M-SSA decomposition procedure is the eigenvalue spectrum in Fig. 6. These eigenvalues of the lag-covariance matrix of the data set give the variances of the successive components.

The eigenvalues are plotted in Fig. 6 vs. their dominant frequency $f$, as suggested by Allen and Smith [1996], rather than vs. their rank $k$, as originally proposed by Vautard and Ghil [1989]; see Appendix B. We note, in this spectrum, a maximum of two nearly equal eigenvalues at the usually reported mean business cycle length of 5-6 years. According to M-SSA, such a pair of eigenvalues could be associated with a roughly periodic oscillation, rather than with a random fluctuation.

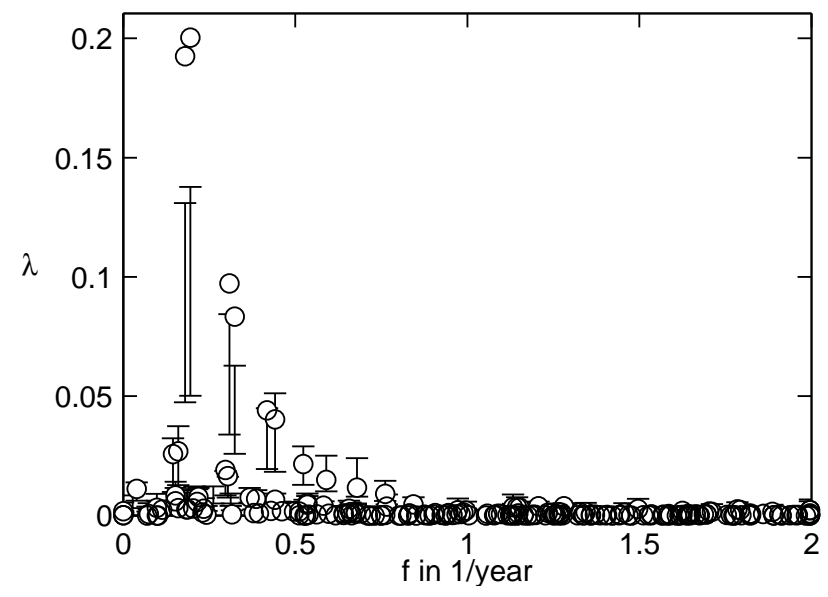

Figure 6. Spectrum of eigenvalues (circles) from M-SSA with a window width of $M=24$. The error bars indicate the $2.5 \%$ and $97.5 \%$ percentile levels of significance, based on Monte Carlo SSA.
Since macroeconomic variables typically exhibit greater variance at lower frequencies, it is quite possible, however, to obtain such a high-variance oscillatory pair even though no truly oscillatory behavior occurs. To ensure that the eigenvalue pair associated with $f \simeq 0.2(\text { year })^{-1}$ is not merely a result of the detrending procedure and thus subject to the Nelson and Kang [1981] criticism of spurious cycles, we submit our set of indicators to Monte Carlo SSA [Allen and Smith, 1996]; the latter approach provides a robust statistical significance test for such oscillations.

Allen and Smith [1996] proposed to fit an autoregressive process of order one, $\operatorname{AR}(1)$, to a scalar, univariate time series, which replicates the variance and decorrelation time of the data but in the absence of oscillations. It is then tested whether the eigenvalues of the given time series exceed the eigenvalue distribution of the AR(1) null hypothesis. The application of Monte Carlo SSA to the multivariate macroeconomic data set at hand, however, requires certain modifications, and takes comovements and detrending effects into account; these necessary modifications are discussed by Groth et al. [2012].

The significance levels obtained in this manner are indicated as error bars in Fig. 6. Like the time series' eigenvalues, the null hypothesis also exhibits a maximum at the fiveyear period and many data eigenvalues do lie between the error bars of the null hypothesis. The two largest eigenvalues, however, stand clearly out above the significance level and thus the related oscillation cannot be merely attributed to the detrending procedure.

Moreover, Groth et al. [2012] demonstrate that this oscillatory mode in the U.S. macroeconomic indicators gains further significance when taking multiple aggregate indicators into account. Indeed an analysis of GDP alone does not show any significant oscillations. The importance of taking the multivariate character of economic activity into account in our analysis is in full agreement with the U.S. National Bureau of Economic Research (NBER) understanding of business cycles as an "activity spread across the economy" and demonstrates the advantage of M-SSA with respect to univariate methods. Groth et al. [2012] also show to what extent the presence of such significant oscillatory mode supports the idea of EnBC dynamics and the presence of deterministic, nonlinear effects.

\subsection{Episodes of high fluctuation levels}

Next, let us accept the results of Fig. 6 and the conclusion that U.S. economic dynamics is indeed characterized by intrinsic oscillatory modes like those captured by the M-SSA reconstructed components (RCs) 1-2 in Fig. 5(b); see again Appendix B for definitions. It is of interest then to evaluate its relative importance vs. that of the residual "noise" associated with the rest of the variability in the data set.

The eigenvalues provide only an average index of the total variance of the associated RCs over the entire time series. Next, we look into time-dependent aspects of the multivariate data set's decomposition and the interplay between the deterministic oscillatory behavior of RCs $1-2$ and the fluctuations in the remaining RCs $3-D M$.

Groth et al. [2012] have analyzed the relative amplitude of the five-year oscillatory activity by means of the local variance fraction as defined by Plaut and Vautard [1994]. This analysis shows a strong time dependency in the oscillationfluctuation decomposition of the U.S. economy with much higher fluctuations during expansions. Groth et al. [2012] verified its statistical significance by means of Monte Carlo SSA against a simple stationary RBC model, and they came to the conclusion that random shocks alone, in the absence of endogenous dynamics, are not sufficient to explain such a strong time dependency in the oscillation-fluctuation decomposition of the U.S. economy. 
This local variance fraction, however, is defined on PCs rather than on RCs, and measures the relative amplitude of oscillatory activity only in a window of the same length $M$ as the one used in M-SSA. Furthermore, the transformation to PCs introduces frequency-dependent phase distortions and complicates the correct assignment of a given variance to a precise instant in time. A subsequent transformation to RCs, on the other hand, neutralizes this undesirable effect [Groth and Ghil, 2011].

For this reason, we propose here a geometric approach based on the RCs and analyze fluctuations perpendicular to a limit cycle; see Appendix B. Figure 5(c) shows the local variance $V=V(t)$ of these fluctuations over a short window of length $L \leq M$, superimposed on the NBER-defined U.S. recessions. Starting after 1980 - and in agreement with the findings of Groth et al. [2012] — the variance of the fluctuations during expansions is much higher than during recessions, as suspected from applying FDT reasoning to the U.S. economy. We thus conclude that the vulnerability paradox obtained when subjecting NEDyM to a sequence of natural-hazard shocks is consistent with a mature economy's greater instability during expansions.

\subsection{Reconstruction of phase-dependent fluctuations}

The fluctuation pattern of the U.S. macroeconomic indicators plotted in Fig. 5 exhibits rapid changes on time scales that are below the M-SSA window length of $M=24$ quarters. Is M-SSA flexible enough to detect changes in the dynamical system's behavior on time scales shorter than $M$ ? In the following example of a stochastically driven oscillator in the plane, we shall demonstrate that M-SSA is indeed capable to track such rapid changes; see Appendix C for further details.
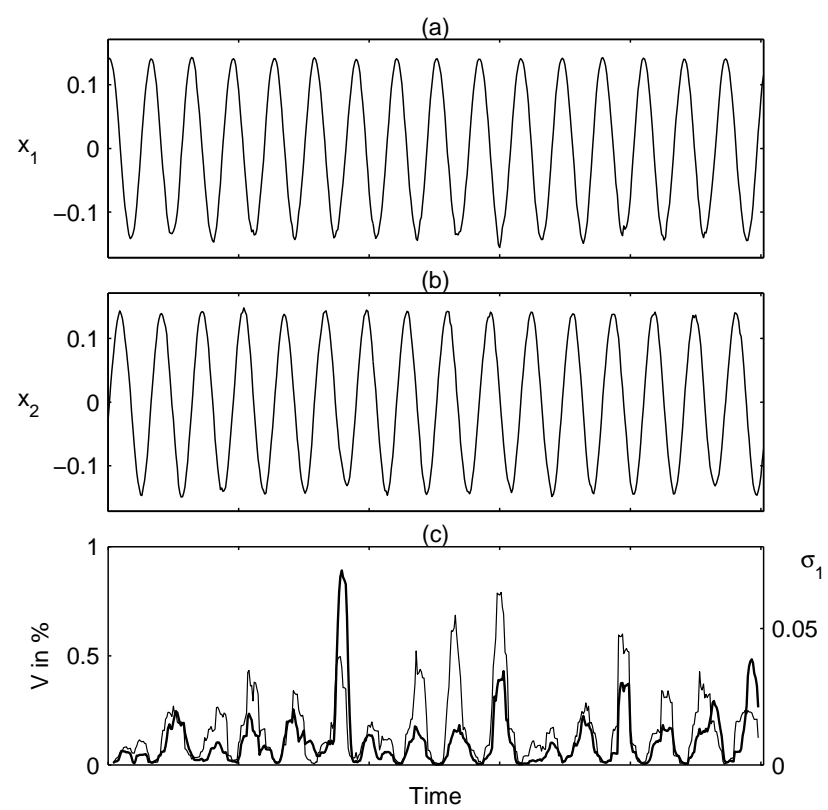

Figure 7. Changes in local variance of a simple, stochastically perturbed oscillator in Eq. (1). (a, b) Typical realization of a solution of the stochastic oscillator, plotted in cartesian coordinates $\left(x_{1}, x_{2}\right)$; and (c) corresponding local variance $\sigma_{1}(t)$ of the stochastic forcing, as given by Eq. (C5) (light solid), along with the estimated local variance $V(t)$ in a sliding window of length $L=11$ (heavy solid). The M-SSA window length is $M=50$.
In polar coordinates $(\rho, \theta)$, this oscillator is given by

$\mathrm{d} \rho=\rho(\mu+c \rho) \mathrm{d} t+\frac{\phi}{\pi} \mathrm{d} W_{1}$,

$\mathrm{d} \phi=\omega \mathrm{d} t+\mathrm{d} W_{2}$.

We introduce phase-dependent variations in the stochastic forcing of the amplitude $\rho$ in Eq. (1) and try to reconstruct this variation.

Starting with the simple case of a circular limit cycle, we choose the parameters in Eq. (1) as $\{c, \mu, \omega\}=\{-0.5,1,1\}$. Then system is integrated from $t=0$ to $t=T=16 \pi$ with a small step size $\Delta t=0.02$ by using a particular noise realization and the Euler-Maruyama scheme [Kloeden and Platen, 1992]. From this integration we keep only every tenth sample value of the trajectory to get the final time series of length $N \simeq 500$. The sampling scheme results in a period length of about 31 samples, and a typical realization is shown in Figs. $7(\mathrm{a}, \mathrm{b})$.

The window length $M=50$ used in Fig. 7 is chosen to cover more than one period of the oscillator, and it is not a critical parameter in this experiment. Beside $M=50$, we have also tested $M=100$ and 200 and found the same results.

The oscillatory mode can be reliably reconstructed by the first oscillatory pair RCs 1-2, and a test with Monte Carlo SSA confirms that only this pair is significant. The sum of the remaining RCs $3-D M$, which represents the fluctuations, is projected on the local perpendiculars to the limit cycle described by RCs 1-2; see Appendix B for details. The local variance $V(t)$ of these fluctuations agrees very well with the local variance $\sigma_{1}(t)$ of the stochastic forcing on $\rho$, cf. Fig. $7(\mathrm{c})$. Without the projection, $V(t)$ would represent a mixture of amplitude and phase forcing in Eq. (1), and a reliable detection of variations in the former would not be possible (not shown).

Next, we wish to evaluate the consequences of a more complex limit cycle geometry, which resembles better that of NEDyM's limit cycle, as shown in Fig. 3 here. Instead of a simple circular limit cycle with constant amplitude, we introduce a phase-dependent amplitude, according to Eq. (C7)
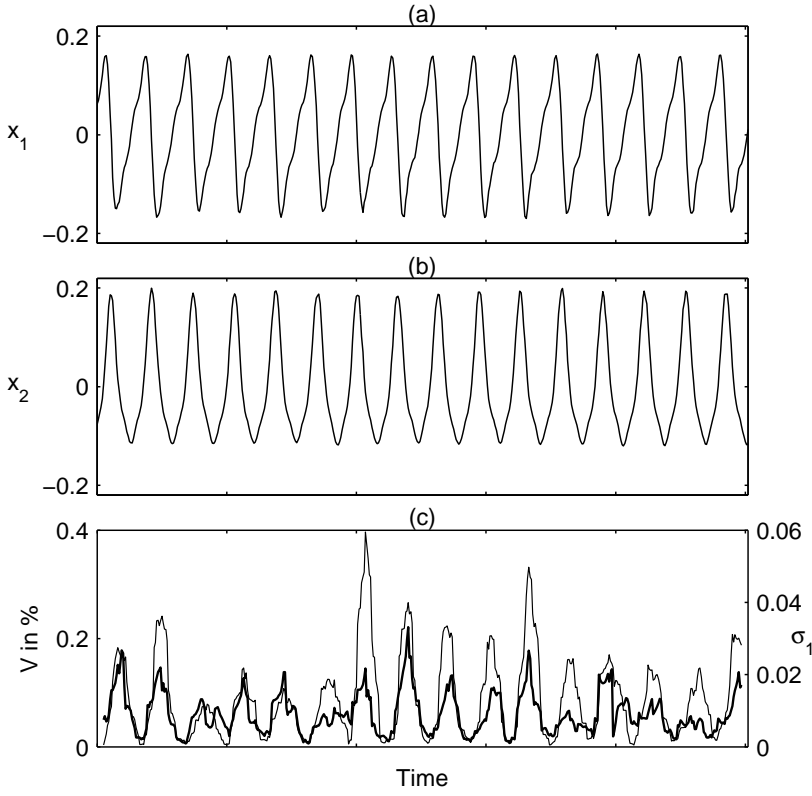

Figure 8. Same as Fig. 7, but for a more complex limit cycle, cf. Eq. (C7). 
This modification introduces higher harmonics of first and second order into the observed time series, and yields a sawtooth shape behavior in $x_{1}$, cf. Fig. 8(a).

The presence of higher harmonics is also reflected in the M-SSA results: three significant oscillatory pairs are detected, and the corresponding RCs $1-6$ give a good reconstruction of the limit cycle. The remaining RCs $7-D M$ still give a good approximation of the fluctuations, and the local variance $V(t)$ of the part that is orthogonal to the RCs $1-6$ reflects very well the changes in the stochastic forcing on the amplitude, as shown in Fig. 8(c).

Although the geometric approach of local variance estimation by means of $V(t)$ in both Figs. 7 and 8 provides a good distinction between epochs of small and large stochastic forcing, it gives only an approximate estimate of the correct variance. A better estimator, however, would require more detailed knowledge about the underlying model dynamics and its response to exogenous shocks, and would lead to nonlinear inverse modeling, as reviewed for instance by Kravtsov et al. [2009]. This is, however, beyond the scope of the present paper and is left for future work.

\section{Concluding remarks}

\subsection{Summary}

In this research-and-review paper, we set out to combine three strands of research: (i) the formulation and study of a non-equilibrium dynamic model (NEDyM) of endogenous business cycles (EnBCs) [Hallegatte et al., 2008]; (ii) the application of this NEDyM model to the investigation of the impact of global warming and extreme events on the economy [Hallegatte et al., 2007; Hallegatte and Dumas, 2008; Hallegatte and Ghil, 2008]; and (iii) the quantitative extraction of business cycles from macroeconomic data [Groth and Ghil, 2011; Groth et al., 2012], including the validation of the FDT hypothesis on the functioning of the U.S. economy.

In Section 2.3, we showed that NEDyM does indeed produce EnBCs, due essentially to the instability of the profitinvestment relationship. NEDyM reproduces the observed asymmetry of business cycles, with the recession phase much shorter than the expansion phase (Fig. 3); it is also consistent with many other stylized facts described in the macroeconomic literature, such as the phasing, or comovements, of the distinct macroeconomic variables along the cycle. The model's main control parameter is investment flexibility, $\alpha_{\text {inv }}$. As this parameter increases, model solutions go from a single stable equilibrium, consistent with the Solow [1956] balanced-growth model, to regular, periodic business cycles and on to irregular, chaotic ones (Fig. 2).

In Section 3, we have further shown that the response of a dynamic economy to natural disasters differs markedly from the one of an economy in generalized equilibrium or undergoing merely balanced growth. The state of an outof-equilibrium economy may affect the consequences of natural disasters, by interfering with reconstruction dynamics. When the investment flexibility favors the presence of business cycles, we found a remarkable vulnerability paradox in NEDyM: The indirect costs caused by extreme events during a growth phase of the economy exceed those that occur during a recession (Fig. 4). The explanation of this apparent paradox is related to a greater instability of the economy during expansions.

Drawing a crude analogy between economic dynamics as the outcome of many interacting "particles" — be they firms, individuals or other entities [Ghil et al., 2008b; Soros, 2008; Coluzzi et al., 2011] — and the particle systems of statistical physics, one might suspect that an out-of-equilibrium version [Ruelle, 2009; Chekroun et al., 2011] of classical fluctuation dissipation theory (FDT) [Einstein, 1905; Kubo, 1966 ] would apply. In particular, we expected to find greater variability during expansion phases in time series of macroeconomic indicators.

The macroeconomic data analysis in Section 4 dealt with multiple indicators for the U.S. economy from 1954 to 2005. Based on a systematic application of multivariate singular spectrum analysis (M-SSA), we have provided evidence for genuinely oscillatory - albeit not purely periodic - modes, which are pervasive in many aggregates. The application of Monte Carlo SSA thus allowed us to reject the hypothesis of purely random shocks generating business cycle dynamics in an otherwise stable economy.

We have compared the predicted vulnerability patterns of NEDyM with the recent findings of state-dependent fluctuations in the U.S. economy, as illustrated here in Fig. 5(c). Groth et al. [2012] have shown that the recession phase is dominated by a deterministic oscillatory mode, while the expansion phase exhibits more complex and irregular dynamics, in agreement with the FDT conjecture.

The latter suggests a higher volatility of business cycles during expansions, and we have demonstrated by introducing and analyzing here a simple nonlinear, stochastically perturbed oscillator that M-SSA is indeed able to track rapid changes in the variance of the stochastic forcing. It is a matter of some interest, as well as some puzzlement, that the more volatile response to external shocks occurs in a loworder model like NEDyM, while the FDT conjecture applies in principle to high-order, "multi-particle" systems. To further verify the greater instability of mature economies during an expansion phase, we have extended the analysis from Groth et al. [2012] and proposed in Section 4.3 and Appendix B2 here a simple geometric, M-SSA-based approach to estimate the local variance of irregular fluctuations along an otherwise deterministic trajectory.

\subsection{Outlook}

Our highly idealized macroeconomic model, however, is still lacking a suitable calibration of its parameters on economic data. The amplitude of the price-and-wage oscillation, for example, is still too large in NEDyM.

To estimate these parameters, we expect to rely on the data assimilation approach. Its use is common by now in many areas of the geosciences [Bengtsson et al., 1981; Ghil, 1997; Kondrashov et al., 2008]; it has also been used in the econometric context [Harvey, 1989] but is only starting to be applied to macroeconomic models [Lemoine and Pelgrin, 2004]. Preliminary results (not reported here) were obtained by applying data assimilation methods, such as Kalman filtering [Kalman, 1960; Ghil et al., 1981] to the NEDyM model, using at first synthetic data produced by the model itself — the so-called "identical-twin" approach [Bengtsson et al., 1981]; these results were encouraging but not conclusive.

Finally, work on truly coupled climate-economy models has started by coupling a very simple, linear climate model to a two-sector dynamic economic model [Dumas, 2006]. In this model, the infrastructure and housing sectors are separated from the rest of the economy; they are assumed to be vulnerable to extreme events but otherwise inert. While the macroeconomic modeling in this coupled climate-economy model is less advanced than in NEDyM, it allows one to represent, in one unified framework, climate prediction and adaptation to climate change impacts, while taking into account the natural variability of both the climate system and the economy.

Suitable calibration of NEDyM, combined with the development of multi-sector economic models along the same lines and the use of more advanced, nonlinear climate models Ghil [2001]; Ghil et al. [2008a], should provide, eventually, a more advanced and realistic unified framework for the truly coupled study of climate and the economy. 
Acknowledgments. A.G. and P.D. have been supported by a grant from the Réseau de Recherche sur le Développement Soutenable (R2DS) of the Région Ile-de-France, while M.G. received partial support from NSF Grant No. DMS-1049253.

\section{Appendix A: NEDyM with shocks}

Our non-equilibrium dynamic model (NEDyM) builds on the key ideas of the classical Solow [1956] balanced-growth model, but it replaces the latter's static relationships by dynamic ones. NEDyM's long-term behavior reproduces the behavior of the Solow model with slowly evolving, perfect market equilibria. The introduction of adjustment delays, however, induces much richer, and arguably more realistic short-term dynamics.

The first part of this appendix gives a brief presentation of NEDyM; see Hallegatte et al. [2008] for a full description. In the second part, we summarize NEDyM modifications used to account for external shocks [Hallegatte et al., 2007].

\section{A1. NEDyM formulation}

In the Solow model, the price $p$ is determined by the equality of production $Y$ and demand $D, Y=D$. In NEDyM, $Y \neq D$ and the goods inventory $H$ is modeled as

$$
\dot{H}=Y-D .
$$

The demand $D$ equals the sum of consumption $C$ and investment $I$,

$$
D=C+I \text {. }
$$

Changes in the price $p$ are driven by the ratio of $H / D$,

$$
\dot{p}=-p \alpha_{\mathrm{p}} \frac{H}{D},
$$

with the price adjustment coefficient $\alpha_{\mathrm{p}}$. As in the Solow model, the Cobb-Douglas [Cobb and Douglas, 1928] production function is used,

$$
Y=f(L, K)=A L^{\lambda} K^{1-\lambda},
$$

where $L$ stands for labor - more precisely the number of employed workers - and $K$ for capital; we use the value $\lambda=2 / 3$ for the capital-for-labor substitution parameter. The parameter $A$ is the total productivity factor.

Instead of full employment $L=L_{\text {full }}=e_{\text {full }} L_{\max }$ in the Solow model, the employment rate evolution follows

$$
\dot{L}=-\frac{1}{\tau_{\mathrm{empl}}}\left(L-L_{\mathrm{e}}\right),
$$

with a characteristic time $\tau_{\text {empl }}$. The optimal labor demand $L_{\mathrm{e}}$ is chosen by the producer to maximizes profits, as a function of real wage and marginal labor productivity,

$$
\frac{w}{p}=\frac{\partial f}{\partial L}\left(L_{\mathrm{e}}, K\right)
$$

The evolution of wages is related to the employment rate,

$$
\dot{w}=\frac{w}{\tau_{\text {wage }}} \frac{L-L_{\text {full }}}{L_{\text {full }}},
$$

with the characteristic time $\tau_{\text {wage }}$. The wages essentially restore the full employment rate by increasing if the labor demand is higher than $L_{\text {full }}$, and decreasing when it is lower.

The capital $K$ evolves here according to

$$
\dot{K}=I-\frac{1}{\tau_{\text {dep }}} K
$$

like in the classical Solow model, with the capital depreciation time $\tau_{\text {dep }}$. In the latter's producer behavior, sales $p D$ equal wages $w L$ plus profits, and investment equals saving.

A key feature of NEDyM is the introduction of an investment module, inspired by Kalecki [1937]. Instead of equating investments and savings, it introduces a stock of liquid assets $F$, held by companies and banks; its evolution follows

$$
\dot{F}=p D-w L+\gamma_{\text {save }} \alpha_{\mathrm{M}} M-\left(1-\Gamma_{\text {inv }}\right) \alpha_{\mathrm{F}} F-p I .
$$

The stock is filled by the difference between sales $p D$ and wages $w L$, as well as by the consumers' savings $\gamma_{\mathrm{save}} \alpha_{\mathrm{M}} M$. These assets are used to redistribute share dividends (1 $\left.\Gamma_{\text {inv }}\right) \alpha_{\mathrm{F}} F$ and to invest in the amount

$$
p I=\Gamma_{\mathrm{inv}} \alpha_{\mathrm{F}} F .
$$

The consumer consumption

$$
C=\left(1-\gamma_{\text {save }}\right) \frac{1}{p} \alpha_{\mathrm{M}} M
$$

is linked to the consumer stock of money $M$, and it is fixed to a specific savings ratio $\gamma_{\text {save }}$. The companies and banks' stock of liquid assets $F$ and the consumer stock of money $M$ sum to a constant value, $F+M=$ const. The evolution of $F$ is linked with the investment ratio dynamics $\Gamma_{\text {inv }}$, which in turn follows

$\dot{\Gamma}_{\mathrm{inv}}= \begin{cases}\alpha_{\mathrm{inv}}\left(\gamma_{\max }-\Gamma_{\mathrm{inv}}\right)\left[\Pi_{\mathrm{n}} /(p K)-\nu\right], & \text { if } \Pi_{\mathrm{n}} /(p K)>\nu, \\ \alpha_{\mathrm{inv}}\left(\Gamma_{\mathrm{inv}}-\gamma_{\min }\right)\left[\Pi_{\mathrm{n}} /(p K)-\nu\right], & \text { if } \Pi_{\mathrm{n}} /(p K) \leq \nu .\end{cases}$

The expected net profit $\Pi_{\mathrm{n}}=p D-w L-\tau_{\text {dep }}^{-1} p K$ follows the accounting definition of Copeland and Weston [2003] and it is compared with a standard of profitability $\nu$; the producer increases or decreases the investments accordingly. The extrema $\gamma_{\min }=0$ and $\gamma_{\min }=0.8$ represent the positivity of investments and a cash-flow constraint, respectively.

The investment dynamics is further governed by the investment coefficient $\alpha_{\text {inv }}$. Seven parameters determine the model equilibrium at $\alpha_{\text {inv }}=0$; they are calibrated to reproduce the state of the European Union's economy in 2001, with 15 countries [Eurostat, 2002]. The other six parameters are chosen, up till now, in an empirical, ad hoc manner; they require calibration by data assimilation methods, as discussed in Section 5.2. All 13 parameter values are given in Table 3 of Hallegatte et al. [2008].

\section{A2. Impacts of natural disasters}

Natural disasters mainly destroy the stock of productive capital and cause disequilibrium effects in model behavior. Hallegatte et al. [2007] presented at some length the modifications of NEDyM that are necessary in order to correctly model disaster consequences.

A simple replacement of the productive capital $K$ by $K-\Delta K$ leads one to underestimate the impact on the production $Y$. For this reason, the authors introduced a further variable $\xi_{\mathrm{K}}$ into the Cobb-Douglas production function of Eq. (A4), namely

$$
Y=\xi_{\mathrm{K}} f(L, K)=\xi_{\mathrm{K}} A L^{\lambda} K^{1-\lambda} .
$$

Furthermore, Hallegatte et al. [2007] introduced inertia into the reconstruction process, by distinguishing between the investments $I_{\mathrm{n}}$ that increase the capital $K$, and reconstruction investments $I_{\mathrm{r}}$ that restore $\xi_{\mathrm{K}}$ to the standard value $\xi_{\mathrm{K}}=1$. Hence, the capital in Eq. (A8) now evolves according to

$$
\dot{K}=\frac{I_{\mathrm{n}}}{\xi_{\mathrm{K}}}-\frac{1}{\tau_{\mathrm{dep}}} K,
$$


and the empirical, shock-response variable $\xi_{\mathrm{K}}$ is modeled as

$$
\dot{\xi}_{\mathrm{K}}=\frac{I_{\mathrm{r}}}{\xi_{\mathrm{K}}}
$$

The authors further limit $I_{\mathrm{r}}$ to a fraction $f_{\max }$ of the total available investment $I=I_{\mathrm{r}}+I_{\mathrm{n}}$, and let

$$
I_{\mathrm{r}}= \begin{cases}\min \left\{f_{\max } I,\left(1-\xi_{\mathrm{K}}\right) K_{0}\right\}, & \text { if } \xi_{\mathrm{K}}<1, \\ 0, & \text { otherwise }\end{cases}
$$

A value of $f_{\max }=5 \%$ means that the economy can mobilize about $1 \%$ of the GDP per year for the reconstruction.

\section{Appendix B: Singular spectrum analysis}

Singular spectrum analysis (SSA) as well as multivariate SSA (M-SSA) rely on the classical Karhunen-Loève spectral decomposition of stochastic processes [Karhunen, 1946; Loève, 1945]. In the context of nonlinear dynamics, Broomhead and King [1986a, b] applied this methodology, long familiar in the stochastic realm, to the reconstruction of a deterministic dynamical system's behavior from observed time series. For this purpose, Broomhead and King applied principal component analysis to the Mañé-Takens idea [Mañé, 1981; Takens, 1981] of a time-delayed embedding, and provided a robust way to extract major directions in the system's phase space.

M. Ghil, R. Vautard and associates first proposed to apply the SSA methodology to the spectral analysis of short and noisy time series, for which standard methods derived from Fourier analysis do not work well [Vautard and Ghil, 1989; Ghil and Vautard, 1991; Vautard et al., 1992]. Ghil et al. [2002] provide an overview and a comprehensive set of references; see also their free software at http://www. atmos.ucla.edu/tcd/ssa/.

\section{B1. Reconstruction of oscillatory behavior}

M-SSA operates on a multivariate time series

$$
\mathbf{x}=\left\{x_{d}(n): d=1 \ldots D, n=1 \ldots N\right\},
$$

with $D$ channels of length $N$. Each channel is embedded into an $M$-dimensional phase space, by using lagged copies

$$
\mathbf{X}_{d}(n)=\left(x_{d}(n), \ldots, x_{d}(n+M-1)\right),
$$

with $n=1, \ldots, N-M+1$. From this extended data set one forms the full augmented trajectory matrix

$$
\mathbf{X}=\left(\mathbf{X}_{1}, \mathbf{X}_{2}, \ldots, \mathbf{X}_{D}\right)
$$

which has $D M$ columns of length $N-M+1$.

The M-SSA algorithm then computes the covariance matrix $\mathbf{C}=\mathbf{X}^{\top} \mathbf{X}$ of $\mathbf{X}$, where $(\cdot)^{\top}$ is the transpose. The sample covariance matrix $\mathbf{C}$ contains all the auto- and crosscovariance information on $\mathbf{X}$, up to a time lag of $M-1$. Due to the finite length of the time series, the matrix $\mathbf{C}$ may deviate slightly from symmetry. Therefore we use here the Toeplitz approach proposed by Vautard and Ghil [1989].

In the algorithm's next step, the Toeplitz matrix $\mathbf{C}$ is diagonalized

$$
\boldsymbol{\Lambda}=\mathbf{E}^{\top} \mathbf{C} \mathbf{E}
$$

to yield a diagonal matrix $\boldsymbol{\Lambda}$ that contains the real eigenvalues $\lambda_{k}$ along the diagonal, and a unitary matrix $\mathbf{E}$ whose columns are the associated eigenvectors $\mathbf{e}_{k}$. These eigenvectors form a new orthogonal basis in the embedding space of $\mathbf{X}$, and the corresponding eigenvalues $\lambda_{k}$ give the variance in the direction of $\mathbf{e}_{k}$. This decomposition helps us find major components of the system's dynamical behavior and reconstruct a robust "skeleton" of the underlying structure. Essentially, these components can be classified into trends, oscillatory patterns and noise.

By projecting the embedded time series $\mathbf{X}$ onto the eigenvectors $\mathbf{E}$,

$$
\mathbf{A}=\mathbf{X} \mathbf{E}
$$

we get the principal components (PCs) arranged as columns in $\mathbf{A}$. We denote the elements of the $k$-th PC by $a_{k}(n)$.

Finally, one can reconstruct that part of the time series that is associated with a particular eigenvector $\mathbf{e}_{k}$ by using the reconstructed components (RCs) introduced by Ghil and Vautard [1991] and Vautard et al. [1992] in the singlechannel and by Keppenne and Ghil [1993] and Plaut and Vautard [1994] in the multi-channel case,

$$
r_{d k}(n)=\frac{1}{M} \sum_{m=1}^{M} a_{k}(n-m+1) e_{d k}(m) .
$$

The notation $\mathbf{e}_{k}=\left\{e_{d k}(m): 1 \leq d \leq D, 1 \leq m \leq M\right\}$ reflects the special structure of the eigenvectors [Groth and Ghil, 2011]; formulas for $r_{d k}(n)$ near the endpoints of the time series are given in Vautard et al. [1992] and Ghil et al. [2002].

Given any subset $\mathcal{K}$ of eigenelements $\left\{\left(\lambda_{k}, \mathbf{e}_{k}\right): k \in \mathcal{K}\right\}$, we obtain the corresponding reconstruction $r_{d \mathcal{K}}$ by summing the RCs $r_{d k}$ over $k \in \mathcal{K}$,

$$
r_{d \mathcal{K}}(n)=\sum_{k \in \mathcal{K}} r_{d k}(n)
$$

Typical choices of $\mathcal{K}$ may involve (i) $\mathcal{K}=\{k: 1 \leq k \leq S\}$, where $S$ is the statistical dimension of the time series, cf. Vautard and Ghil [1989], i.e., the number of statistically significant components, commonly referred to as the signal, as opposed to the noise; or (ii) a so-called oscillatory pair $\mathcal{K}=\left\{k_{1}, k_{2}\right\}$, which might capture a possibly cyclic mode of behavior of the system [Vautard and Ghil, 1989; Plaut and Vautard, 1994].

Information about oscillatory modes can help detect clusters of phase- and frequency-locked oscillators even in the presence of high observational noise [Groth and Ghil, 2011]. Summing over the whole set of RCs, $\mathcal{K}=\{k: 1 \leq k \leq D M\}$, gives the complete reconstruction of the time series.

\section{B2. Reconstruction of fluctuations}

Here, we propose M-SSA as a tool to help quantify the intensity of fluctuations along a limit cycle. Our proposal relies on the smooth behavior of the band-limited RCs, which enables a quantification of the fluctuations that are orthogonal to the system's supposedly deterministic trajectory.

Let us assume that RCs $1-S$ represent this deterministic part and the remaining RCs represent irregular fluctuations. We denote the two parts by $\mathbf{r}_{\mathcal{K}}=\left(r_{1 \mathcal{K}}, \ldots, r_{D \mathcal{K}}\right)$ and $\mathbf{r}_{\mathcal{K}^{\prime}}=$ $\left(r_{1 \mathcal{K}^{\prime}}, \ldots, r_{D \mathcal{K}^{\prime}}\right)$, respectively, with $\mathcal{K}=\{k: 1 \leq k \leq S\}$ and $\mathcal{K}^{\prime}=\{k: S+1 \leq k \leq D M\}$. From this we determine the part of the fluctuations $\mathbf{r}_{\mathcal{K}^{\prime}}(n)$ that is orthogonal to the temporal evolution $\Delta \mathbf{r}_{\mathcal{K}}(n)=\mathbf{r}_{\mathcal{K}}(n-1)-\mathbf{r}_{\mathcal{K}}(n+1)$ of the deterministic part:

$$
\mathbf{r}_{\mathcal{K}^{\prime}}^{\perp}(n)=\mathbf{r}_{\mathcal{K}^{\prime}}(n)-\frac{\left\langle\mathbf{r}_{\mathcal{K}^{\prime}}(n), \Delta \mathbf{r}_{\mathcal{K}}(n)\right\rangle}{\left\|\Delta \mathbf{r}_{\mathcal{K}}(n)\right\|^{2}} \cdot \Delta \mathbf{r}_{\mathcal{K}}(n)
$$

the notations $\langle\cdot, \cdot\rangle$ and $\|\cdot\|$ above refer to the scalar product and the norm, respectively.

Since the RCs are smooth, band-limited time series, $\Delta \mathbf{r}_{\mathcal{K}}$ gives a good approximation of the temporal evolution of the trajectory $\mathbf{r}_{\mathcal{K}}$. Once we have derived the orthogonal fluctuations $\mathbf{r}_{\mathcal{K}^{\prime}}^{\perp}$, this smoothness allows us to quantify the average 
amplitude of the fluctuations around the deterministic part with respect to the time series' expansion in a centered window of length $L \leq M$, where $L=2 l+1$ is odd:

$$
V(n)=\frac{\sum_{s=n-l}^{n+l}\left\|\mathbf{r}_{\mathcal{K}^{\prime}}^{\perp}(s)\right\|^{2}}{\sum_{s=n-l}^{n+l}\|\mathbf{x}(s)\|^{2}} .
$$

\section{Appendix C: A randomly forced oscillator}

Our oscillator's deterministic part is given, in cartesian coordinates, by the equations

$$
\begin{aligned}
& \dot{x}_{1}=\mu x_{1}-\omega x_{2}+c x_{1}\left(x_{1}^{2}+x_{2}^{2}\right) \\
& \dot{x}_{2}=\mu x_{2}+\omega x_{1}+c x_{2}\left(x_{1}^{2}+x_{2}^{2}\right) .
\end{aligned}
$$

For $c<0$ and $\mu<0$ the system has a unique, stable fixed point at the origin $\left(x_{1}, x_{2}\right)=(0,0)$. At $\mu=0$ it undergoes a supercritical Hopf bifurcation to a stable limit cycle with frequency $\omega$.

Transformation to polar coordinates, $x_{1}+\mathrm{i} x_{2}=$ $\rho^{1 / 2} \exp \{\mathrm{i} \phi\}$, reduces $(\mathrm{C} 1)$ to the more transparent form

$\dot{\rho}=\rho(\mu+c \rho)$,

$\dot{\theta}=\omega$.

We perturb this oscillator in the plane by two independent Wiener processes $W_{1,2}$, each of which has independent increments $\mathrm{d} W_{1,2}$ of variance $\{0.4 \mathrm{~d} t, 0.02 \mathrm{~d} t\}$. We further introduce a phase-dependent variation of the forcing on $\rho$, and obtain the stochastic model

$\mathrm{d} \rho=\rho(\mu+c \rho) \mathrm{d} t+\frac{\phi}{\pi} \mathrm{d} W_{1}$,

$\mathrm{d} \phi=\omega \mathrm{d} t+\mathrm{d} W_{2}$.

In order to compare the stochastic forcing on $\rho$ with the M-SSA results, we keep track of the effective shocks on $\rho$ in each interval between two sampling times, $t_{n} \leq t \leq t_{n+1}$

$$
\Delta W_{1}(n)=\pi^{-1} \int_{t_{n}}^{t_{n+1}} \phi(t) \mathrm{d} W_{1} .
$$

and estimate the local variance in a centered window whose length $L=2 l+1 \leq M$ is odd-valued by

$$
\sigma_{1}(n)=L^{-1} \sum_{s=n-l}^{n+l} \Delta W_{1}^{2}(s) .
$$

The observations on system (C3) are in polar coordinates and, prior to applying M-SSA, we have to transform them back into Cartesian coordinates. This is done in one of two distinct ways:

$$
\begin{aligned}
& x_{1}=\rho^{1 / 2} \cos \phi, \\
& x_{2}=\rho^{1 / 2} \sin \phi ;
\end{aligned}
$$

or

$$
\begin{aligned}
& x_{1}=\rho^{1 / 2}\left(1+\sin \phi+\sin ^{2} \phi\right) \cos \phi, \\
& x_{2}=\rho^{1 / 2}\left(1+\sin \phi+\sin ^{2} \phi\right) \sin \phi .
\end{aligned}
$$

The first transformation (C6) yields a circular limit cycle, according to Eq. (C1), while the second transformation (C7) introduces a phase-dependent amplitude and leads to a deformation of the circular structure.

\section{References}

Allen, M. R., and L. A. Smith (1996), Monte Carlo SSA: Detecting irregular oscillations in the presence of colored noise., J. Clim., 9, 3373-3404, doi:10.1175/1520-0442(1996)009/3373: MCSDIO $>2.0 . \mathrm{CO} ; 2$.

Ambrosi, P., J.-C. Hourcade, S. Hallegatte, F. Lecocq, P. Dumas, and M. Ha-Duong (2003), Optimal control models and elicitation of attitudes towards climate change, Environ. Model. Assess., 8(3), 135-147, doi:10.1023/A:1025586922143.

Bank, W. (1999), Turkey: Marmara Earthquake Assessment, vol. 27380, Turkey Country Office, The World Bank, Washington, DC

Bengtsson, L., M. Ghil, and E. Källén (Eds.) (1981), Dynamic Meteorology: Data Assimilation Methods, 330 pp., SpringerVerlag, New York/Heidelberg/Berlin.

Benhabib, J., and K. Nishimura (1979), The Hopf-bifurcation and the existence of closed orbits in multi-sectoral models of optimal economic growth, J. Econ. Theory, 21, 421-444.

Benson, C., and E. Clay (2004), Understanding the Economic and Financial Impact of Natural Disasters, The International Bank for Reconstruction and Development. The World Bank, Washington, DC.

Broomhead, D. S., and G. P. King (1986a), Extracting qualitative dynamics from experimental data, Physica D, 20(2-3), 217-236, doi:10.1016/0167-2789(86)90031-X.

Broomhead, D. S., and G. P. King (1986b), On the qualitative analysis of experimental dynamical systems, in Nonlinear Phenomena and Chaos, edited by S. Sarkar, pp. 113-144, Adam Hilger, Bristol, England.

Burns, A. F., and W. C. Mitchell (1946), Measuring Business Cycles, NBER, New York City, New York.

Chekroun, M. D., D. Kondrashov, and M. Ghil (2011), Predicting stochastic systems by noise sampling, and application to the El Niño-Southern Oscillation, Proc. Natl. Acad. Sci. USA, 108(29), 11,766-11,771, doi:10.1073/pnas.1015753108.

Chiarella, C., and Flaschel (2000), The Dynamics of Keynesian Monetary Growth, Cambridge University Press.

Chiarella, C., P. Flaschel, and R. Franke (2005), Foundations for a Disequilibrium Theory of the Business Cycle, Cambridge University Press.

Chiarella, C., R. Franke, P. Flaschel, and W. Semmler (2006), Quantitative and Empirical Analysis of Nonlinear Dynamic Macromodels, 277 pp., Elsevier.

Cobb, C. W., and P. H. Douglas (1928), A theory of production, Am. Econ. Rev., 18(1), 139-165.

Coluzzi, B., M. Ghil, S. Hallegatte, and G. Weisbuch (2011), Boolean delay equations on networks in economics and the geosciences, Int. J. Bifurcat. Chaos, in press.

Copeland, T. E., and J. F. Weston (2003), Financial Theory and Corporate Policy, 3rd ed., Pearson Education International, Prentice Hall, Upper Saddle River, New Jersey, USA.

Day, R. (1982), Irregular growth cycles, Am. Econ. Rev., 72, 406414.

Dumas, P. (2006), L'évaluation des dommages du changement climatique en situation d'incertitude: l'apport de la modélisation des coûts de l'adaptation, Thèse de doctorat, École des Hautes Études en Sciences Sociales, Paris.

Einstein, A. (1905), Über die von der molekularkinetischen Theorie der Wärme geforderte Bewegung von in ruhenden Flüssigkeiten suspendierten Teilchen, Annalen der Physik, 322 (8), 549-560, doi:10.1002/andp.19053220806.

Eurostat (2002), Economic Portrait of the European Union 2001, European Commission, Brussels.

Flaschel, P., R. Franke, and W. Semmler (1997), Dynamic Macroeconomics: Instability, Fluctuations and Growth in Monetary Economies, MIT Press.

Frisch, R. (1933), Propagation problems and impulse problems in dynamic economics, in Economic Essay in honor of Gustav Cassel, pp. 171-206, George Allen and Unwin, London.

Gale, D. (1973), Pure exchange equilibrium of dynamic economic models, J. Econ. Theory, 6, 12-36. 
Ghil, M. (1997), Advances in sequential estimation for atmospheric and oceanic flows, J. Meteor. Soc. Japan, 75(1B), 289304.

Ghil, M. (2001), Hilbert problems for the geosciences in the 21st century, Nonlin. Proc. Geophys., 8, 211-222.

Ghil, M., and R. Vautard (1991), Interdecadal oscillations and the warming trend in global temperature time series, Nature, 350(6316), 324-327, doi:10.1038/350324a0.

Ghil, M., S. Cohn, J. Tavantzis, K. Bube, and E. Isaacson (1981), Applications of estimation theory to numerical weather prediction, in Dynamic Meteorology: Data Assimilation Methods, edited by L. Bengtsson, M. Ghil, and E. Källén, pp. 139-224, Springer-Verlag.

Ghil, M., M. R. Allen, M. D. Dettinger, K. Ide, D. Kondrashov, M. E. Mann, A. W. Robertson, A. Saunders, Y. Tian, F. Varadi, and P. Yiou (2002), Advanced spectral methods for climatic time series, Rev. Geophys., 40(1), 1-41, doi: 10.1029/2000RG000092.

Ghil, M., M. Chekroun, and E. Simonnet (2008a), Climate dynamics and fluid mechanics: Natural variability and related uncertainties, Physica D, 237, 2111-2126.

Ghil, M., I. Zaliapin, and B. Coluzzi (2008b), Boolean delay equations: A simple way of looking at complex systems, Physica D, 237(23), 2967-2986, doi:10.1016/j.physd.2008.07.006.

Goodwin, R. (1951), The non-linear accelerator and the persistence of business cycles, Econometrica, 19, 1-17.

Goodwin, R. (1967), A growth cycle, in Socialism, Capitalism and Economic Growth, edited by C. Feinstein, Cambridge University Press, Cambridge.

Grandmont, J.-M. (1985), On endogenous competitive business cycles, Econometrica, 5, 995-1045.

Groth, A., and M. Ghil (2011), Multivariate singular spectrum analysis and the road to phase synchronization, Phys. Rev. E, 84, 036,206, doi:10.1103/PhysRevE.84.036206.

Groth, A., M. Ghil, S. Hallegatte, and P. Dumas (2012), The role of oscillatory modes in the U.S. business cycle, submitted.

Hahn, F., and R. Solow (1995), A Critical Essay on Modern Macroeconomic Theory, The MIT Press, Cambridge, Massachussetts and London, England.

Hallegatte, S., and P. Dumas (2008), Can natural disasters have positive consequences? Investigating the role of embodied technical change, Ecol. Econ., doi:doi:10.1016/j.ecolecon.2008. 06.011 .

Hallegatte, S., and M. Ghil (2008), Natural disasters impacting a macroeconomic model with endogenous dynamics, Ecol. Econ., 68(1-2), 582-592, doi:doi:10.1016/j.ecolecon.2008.05. 022 .

Hallegatte, S., J.-C. Hourcade, and P. Dumas (2007), Why economic dynamics matter in assessing climate change damages: illustration on extreme events, Ecol. Econ., 62, 330-340, doi: 10.1016/j.ecolecon.2006.06.006.

Hallegatte, S., M. Ghil, P. Dumas, and J.-C. Hourcade (2008), Business cycles, bifurcations and chaos in a neo-classical model with investment dynamics, J. Econ. Behav. Organ., 67(1), 5777, doi:10.1016/j.jebo.2007.05.001.

Harrod, R. (1939), An essay on dynamic economic theory, Econ. J., 49, 1433.

Harvey, A. C. (1989), Forecasting, Structural Time Series Models and the Kalman Filter, Cambridge University Press.

Hicks, J. (1950), The cycle in outline, in A Contribution to the Theory of the Trade Cycle, pp. 95-107, Oxford University Press, Oxford, ch. 8.

Hillerbrand, R., and M. Ghil (2008), Anthropogenic climate change: Scientific uncertainties and moral dilemmas, Physica D, 237, 2132-2138, doi:10.1016/j.physd.2008.02.015.

Hillinger, C. (1992), Cyclical Growth in Market and Planned Economies, Oxford University Press.

Hodrick, R., and E. Prescott (1997), Postwar U.S. business cycles: an empirical investigation, J. Money Credit Bank, 29(1), $1-16$.

IPCC (2007), Climate Change 2007: The Physical Science Basis, 996 pp., Cambridge University Press, contribution of Working Group I to the Fourth Assessment Report of the Intergovernmental Panel on Climate Change.

Jarsulic, M. (1993), A nonlinear model of the pure growth cycle, J. Econ. Behav. Organ., 22(2), 133-151.

Kaldor, N. (1940), A model of the trade cycle, Economic Journal, 50, 78-92.
Kalecki, M. (1937), A theory of the business cycle, Review of Economic Studies, 4, 77-97.

Kalman, R. E. (1960), A new approach to linear filtering and prediction problems, J. Basic. Eng. T. ASME, 82, 5-45, Series D.

Karhunen, K. (1946), Zur Spektraltheorie stochastischer Prozesse, Ann. Acad. Sci. Fenn. Ser. A1, Math. Phys., 34.

Keppenne, C. L., and M. Ghil (1993), Adaptive filtering and prediction of noisy multivariate signals: An application to subannual variability in atmospheric angular momentum, Int. J. Bifurcat. Chaos, 3, 625-634.

Kimball, M. S. (1995), The quantitative analytics of the basic neomonetarist model, J. Money Credit Bank, 27, 1241-1277.

King, R., and S. Rebelo (2000), Resuscitating real business cycles, in Handbook of Macroeconomics, edited by J. Taylor and M. Woodford, pp. 927-1007, North-Holland, Amsterdam.

Kloeden, P. E., and E. Platen (1992), Numerical solutions of stochastic differential equations, 632 pp., Springer, Applications of Mathematics 23.

Kondrashov, D., C. Sun, and M. Ghil (2008), Data assimilation for a coupled ocean-atmosphere model. Part II: Parameter estimation, Mon. Wea. Rev., 136, 5062-5076, doi: 10.1175/2008MWR2544.1.

Kravtsov, S., D. Kondrashov, and M. Ghil (2009), Empirical model reduction and the modeling hierarchy in climate dynamics, in Stochastic Physics and Climate Modelling, edited by T. N. Palmer and P. Williams, pp. 35-72, Cambridge Univ. Press, Cambridge/New York.

Kubo, R. (1966), The fluctuation-dissipation theorem, Reports Progress Physics, 29, 255-284.

Kydland, F., and E. Prescott (1982), Time to build and aggregate fluctuations, Econometrica, 50(6), 1345-1370.

Kydland, F. E., and E. C. Prescott (1998), Business cycles: Real facts and a monetary myth, in Real Business Cycles: A Reader, edited by K. D. S. James E. Hartley, Kevin D. Hoover, Routledge.

Lemoine, M., and F. Pelgrin (2004), Introduction aux modèles espace-état et au filtre de Kalman, Revue de l'OFCE, 86.

Loève, M. (1945), Fonctions aléatoires de second ordre, Comptes Rendus de l'Académie des sciences Paris, 220, 380.

Lucas, R. E., Jr. (1972), Expectations and the neutrality of money, Journal of Economic Theory, 4(2), 103-124.

Lucas, R. E., Jr. (1973), Some international evidence on outputinflation tradeoffs, The American Economic Review, 63(3), 326-334.

Mañé, R. (1981), On the dimension of the compact invariant sets of certain non-linear maps, in Dynamical Systems and Turbulence, Lecture Notes in Mathematics, vol. 898, pp. 230-242, Springer, Berlin, doi:10.1007/BFb0091916.

Moss, R. H., J. A. Edmonds, K. A. Hibbard, M. R. Manning, S. K. Rose, D. P. van Vuuren, T. R. Carter, S. Emori, M. Kainuma, T. Kram, G. A. Meehl, J. F. B. Mitchell, N. Nakicenovic, K. Riahi, S. J. Smith, R. J. Stouffer, A. M. Thomson, J. P. Weyant, and T. J. Wilbanks (2010), The next generation of scenarios for climate change research and assessment, Nature, 463, 744-756, doi:10.1038/nature08823.

Nelson, C. R., and H. Kang (1981), Spurious periodicity in inappropriately detrended time series, Econometrica, 49(3), 741751.

Nikaido, H. (1996), Prices, Cycles, and Growth, 285 pp., MIT Press, Cambridge, MA.

Nordhaus, W. D., and J. Boyer (1998), Roll the DICE Again: The Economics of Global Warming, Yale University.

Plaut, G., and R. Vautard (1994), Spells of low-frequency oscillations and weather regimes in the northern hemisphere, J. Atmos. Sci., 51(2), 210-236, doi:10.1175/1520-0469(1994) 051<0210:SOLFOA $\rangle 2.0 . \mathrm{CO} ; 2$.

Ricardo, D. (1810), The High Price of Bullion, a Proof of the Depreciation of Bank Notes, John Murray, London.

Ruelle, D. (2009), A review of linear response theory for general differentiable dynamical systems, Nonlinearity, 22, 855-870.

Samuelson, P. (1939), A synthesis of the principle of acceleration and the multiplier, J. Polit. Econ., 47, 786-797.

Sargent, T. J. (1971), A note on the "accelerationist" controversy, Journal of Money, Credit and Banking, 3(3), 721-725.

Sargent, T. J. (1973), Rational expectations, the real rate of interest, and the natural rate of unemployment, Brookings Papers on Economic Activity, 1973(2), 429-480. 
Slutsky, E. (1927), The summation of random causes as a source of cyclic processes, III(1), Conjuncture Institute, Moscow, Reprinted in Econometrica, 5, 105-146.

Smith, A. (1776), An Inquiry into the Nature And Causes of the Wealth of Nations, London.

Solow, R. M. (1956), A contribution to the theory of economic growth, $Q . J$. Econ. 70, 65-94.

Soros, G. (2008), The New Paradigm for Financial Markets: The Credit Crisis of 2008 and What It Means, BBS, PublicAffairs, New York.

Stern, N. (2006), The Economics of Climate Change. The Stern Review, 712 pp., Cambridge University Press.

Takens, F. (1981), Detecting strange attractors in turbulence, in Dynamical Systems and Turbulence, Lecture Notes in Mathematics, vol. 898, pp. 366-381, Springer, Berlin.

Vautard, R., and M. Ghil (1989), Singular spectrum analysis in nonlinear dynamics, with applications to paleoclimatic time series, Physica D, 35(3), 395-424, doi:10.1016/0167-2789(89) 90077-8.

Vautard, R., P. Yiou, and M. Ghil (1992), Singular-spectrum analysis: A toolkit for short, noisy chaotic signals, Physica D, 58(1-4), 95-126, doi:10.1016/0167-2789(92)90103-T.

Wittgenstein, L. (2001), Philosophical Investigations, 246 pp., Wiley-Blackwell.

A. Groth and M. Ghil, Environmental Research \& Teaching Institute, Ecole Normale Supérieure, 24 rue Lhomond, 75230 Paris cedex 05, France. \{andreas.groth, michael.ghil\}@ens.fr

P. Dumas and S. Hallegatte, Centre International de Recherche sur l'Environnement et le Développement, Campus du Jardin Tropical, 45 bis avenue de la Belle Gabrielle, 94736 Nogent-surMarne Cedex, France. \{dumas, hallegatte\}@centre-cired.fr 